\section{Classification of Ralstonia pickettii biovar 3/' thomasii' strains (Pickett 1994) and of new isolates related to nosocomial recurrent meningitis as Ralstonia mannitolytica sp. nov.}

1 Department of Clinical Chemistry, Microbiology \& Immunology, Blok A, Ghent University Hospital, De Pintelaan 185, B-9000 Ghent, Belgium

2 Medical Microbiology Unit, University of Louvain, Avenue Hippocrate 54, 1200 Brussels, Belgium

3 Laboratorium voor Microbiologie, Fac. Wetenschappen, Vakgroep WE10V, Ledeganckstraat 35, B-9000 Ghent, Belgium

4 Applied Microbiology Division, National Institute of Bioscience and Human Technology, 1-1 Higashi, Tsukuba-shi, Ibaraki 305-8566, Japan

\author{
Thierry De Baere, ${ }^{1}$ Sophia Steyaert, ${ }^{1}$ Georges Wauters, ${ }^{2}$ Paul De Vos, ${ }^{3}$ \\ Johan Goris, ${ }^{3}$ Tom Coenye, ${ }^{3}$ Tetsushi Suyama, ${ }^{4}$ Gerda Verschraegen ${ }^{1}$ \\ and Mario Vaneechoutte ${ }^{1}$ \\ Author for correspondence: Mario Vaneechoutte. Tel: +329240 36 92. Fax: +3292403659. \\ e-mail: Mario.Vaneechoutte@rug.ac.be
}

Keywords: Ralstonia pickettii biovar 3/'thomasii', Ralstonia mannitolytica sp. nov., infection

\section{INTRODUCTION}

The genus Ralstonia (Yabuuchi et al., 1995) has been created for a group of organisms from ecologically diverse niches to accommodate bacteria that were formerly classified as members of Burkholderia

Abbreviation: TSA, tryptic soy agar.

The GenBank/EMBL/DDBJ accession numbers for the 16S rDNA sequences reported in this paper are AJ270252-AJ270266 and AJ271437.
(Yabuuchi et al., 1992) and Alcaligenes. The type species of the genus, Ralstonia pickettii, was originally regarded as the only representative of clinical importance (Dimech et al., 1993; Fass \& Barnishan, 1976; Fujita et al., 1981; Gardner \& Shulman, 1984; Kahan et al., 1983; Lacey \& Want, 1991; Raveh et al., 1993; Roberts et al., 1990; Verschraegen et al., 1985). Only recently, the taxonomy of this genus has begun to be elucidated with the description of several new species, Ralstonia paucula, Ralstonia gilardii and Ralstonia basilensis, some of which are of moderate 
clinical importance (Coenye et al., 1999; Vandamme et al., 1999; Moissenet et al., 1999; Osterhout et al., 1998; Steinle et al., 1998).

Historically, R. pickettii was created for a group of clinical isolates (Ralston et al., 1973) and also turned out to include strains of CDC group Va-2 (Tatum et al., 1974; Riley \& Weaver, 1975) and possibly other strains. The CDC groups Va-2 and Va-1 were regarded as two different biovars and hence Pickett \& Greenwood (1980) decided that CDC groups Va-1 and Va-2 represented two different biovars of $R$. ('Pseudomonas') pickettii. Shortly before this, King et al. (1979) had concluded that $R$. ('Pseudomonas') pickettii contained several biovars, including the strains originally isolated from clinical samples in St Thomas' Hospital, London, UK (Phillips \& Eykyn, 1972; Phillips et al., 1972), and which had been designated 'Pseudomonas thomasii'. Although this name was never validated, it has been used several times (Baird et al., 1976; King et al., 1979; Costas et al., 1990). According to Pickett (1994), the present taxonomic situation of R. pickettii should be reduced to the recognition of three biovars, with biovar 1 equal to CDC group Va-1, biovar 2 equal to CDC group Va-2 and biovar 3 mostly consistent with the invalid 'Pseudomonas thomasii' (Pickett, 1994).

Here, we report a case of recurrent nosocomial meningitis caused by a colistin-resistant, Gram-negative rod that was identified by means of API $20 \mathrm{NE}$ as Pseudomonas fluorescens. Because of its colistin resistance, this strain was studied in more detail, which lead to its identification as $R$. pickettii biovar $3 /$ 'thomasii'. The further data gathered, by means of sequence determination of the $16 \mathrm{~S}$ rDNA, determination of the cellular fatty acid composition, DNA hybridization, SDS-PAGE and extensive characterization of biochemical reactivity, indicate that this biovar can be considered as a separate species within the genus Ralstonia, named Ralstonia mannitolytica sp. nov. after its characteristic acidification of mannitol, distinct from all other described Ralstonia species. Retrospectively, a strain stored previously as $P$. fluorescens and isolated repeatedly from an abdominal haematoma of a patient with cholangiocarcinoma and a strain from an outbreak due to contaminated water in the neonatal intensive care department of the Ghent University Hospital, Belgium (GUH), in 1990 could also be identified as $R$. mannitolytica. Several nosocomial outbreaks with $R$. pickettii biovar $3 /$ ' thomasii', mostly due to contaminated fluids, have been described (Costas et al., 1990; Pan et al., 1992; Phillips et al., 1972), but no life-threatening infections have been reported yet to our knowledge.

\section{METHODS}

Bacterial strains. The strains studied are listed in Table 1. The clinical strains LMG 19090, LMG 19091 and LMG 19092 were isolated at the GUH. Strain LMG 19090 (LBV407/ UCL310) was isolated repeatedly from a patient with recurrent meningitis (patient 1), strain LMG 19091 (LBV371/RAL13) was isolated repeatedly from an abdominal haematoma of a patient with cholangiocarcinoma (patient 2) and strain LMG 19092 (PSE061) was one of several strains isolated during an outbreak due to contaminated water at the GUH neonatal intensive care department in 1990. Strains LMG 19083 (RAL05/ML7), LMG 19087 (RAL07/YL13), LMG 19088 (RAL06/ML10) and LMG 19089 (RAL04/MC5) are environmental soil isolates described by Suyama et al. (1998) and were included because some of these strains showed the highest 16S rDNA sequence similarity to the clinical strains of all the sequences available from the GenBank/EMBL database. All other strains studied here, including the $R$. mannitolytica type strain (LMG 6866 ${ }^{\mathrm{T}}$ ), were supplied by the BCCM/LMG Bacteria Collection (Ghent, Belgium) or were isolated at the GUH. [Pseudomonas] syzygii strains, which are so closely related to Ralstonia solanacearum (Brim et al., 1998; this study) that they can be regarded as members of this genus, were included to exclude synonymy with the $R$. pickettii biovar 3/'thomasii' strains studied here.

Biochemical characterization. Growth at 30 and $37^{\circ} \mathrm{C}$ was evaluated on tryptic soy agar (TSA) (Sanofi Diagnostics Pasteur). Growth at $42{ }^{\circ} \mathrm{C}$ was tested by adding two drops of a McFarland suspension 3 in water, prepared from a $24 \mathrm{~h}$ culture on TSA, to $5 \mathrm{ml}$ of tryptic soy broth and subsequent incubation in a water bath at $42^{\circ} \mathrm{C}$ and reading after $48 \mathrm{~h}$. Conventional tests were carried out as described elsewhere (Gilligan, 1995). Commercial tests (API ZYM, API 20NE, API $50 \mathrm{CH}$ and ID $32 \mathrm{GN}$; bioMérieux) were carried out according to the instructions of the manufacturer. Assimilation testing was carried out using the AUX medium (bioMérieux). To test for assimilation and alkalinization of organic substrates, Simmons' citrate agar was used, whereby citrate was replaced by organic substrates at a concentration of $0.2 \%(\mathrm{w} / \mathrm{v})$. Desferrioxamine susceptibility was tested according to a method adapted from Lindsay \& Riley (1991), by loading $6 \mathrm{~mm}$ diameter paper discs with $250 \mu \mathrm{g}$ desferal on Müller Hinton II agar (MHA) (BBL Becton Dickinson). Alkaline phosphatase, pyrrolidonyl arylamidase and benzyl arginine arylamidase (trypsin) were tested using Rosco tablets (Taastrup, Denmark) and read after $4 \mathrm{~h}$. Colistin susceptibility was tested using $10 \mu \mathrm{g}$ colistin paper disks (BBL) on MHA and susceptibility to the vibriostatic agent O:129 was tested with Sanofi Diagnostics Pasteur paper discs on MHA. Acidification of ethylene glycol was tested as described previously (Wauters et al., 1998). Staining of flagella was done as described previously (Kodaka et al., 1982).

16S rDNA sequence determination. Amplification was done by PCR with primers named $\alpha \beta$ NOT (5'-AGTTTGATCCTGGCTCAG-3') and $\omega \mathrm{MB}\left(5^{\prime}\right.$-TACCTTGTTACGACTTCGTCCCA-3'). The reactions were performed in a final reaction mixture of $50 \mu \mathrm{l}$ containing $25 \mu \mathrm{l}$ Master Mix (Qiagen), $0 \cdot 2 \mu \mathrm{M}$ of each primer and $5 \mu \mathrm{l}$ of a DNA suspension obtained by alkaline lysis. The amplification reactions were performed in a GeneAmp PCR System 9600 (Perkin-Elmer Applied Biosystems) with the following cycling parameters: $94^{\circ} \mathrm{C}$ for $5 \mathrm{~min}$, followed by three cycles of $45 \mathrm{~s}$ at $94^{\circ} \mathrm{C}, 2 \mathrm{~min}$ at $50{ }^{\circ} \mathrm{C}$ and $1 \mathrm{~min}$ at $72^{\circ} \mathrm{C}$ and 30 cycles of $20 \mathrm{~s}$ at $94{ }^{\circ} \mathrm{C}, 1 \mathrm{~min}$ at $50^{\circ} \mathrm{C}$ and $1 \mathrm{~min}$ at $72{ }^{\circ} \mathrm{C}$, with a final extension at $72{ }^{\circ} \mathrm{C}$ for $7 \mathrm{~min}$. The amplification products were checked by $2 \%$ agarose gel electrophoresis and staining with ethidium bromide. The amplification products were purified with a PCR purification kit (Qiagen) according to the manufacturer's instructions. Sequencing 


\section{Table 1 List of strains studied}

Names of taxa in brackets indicate that the organisms were misnamed at the corresponding taxonomic level. Abbreviations: ATCC, American Type Culture Collection, Manassas, VA, USA; CDC, Centers for Disease Control, Atlanta, GA, USA; CIP, Collection Institut Pasteur, Paris, France; DSM, Deutsche Sammlung von Mikroorganismen, Braunschweig, Germany; GUH, Ghent University Hospital, Belgium; LMG, BCCM/LMG Bacteria Collection, Laboratorium voor Microbiologie, Universiteit Gent, Belgium; NCIB, National Collection of Industrial Bacteria, Aberdeen, UK; NCPPB, National Collection of Plantpathogenic bacteria, Harpenden Laboratory, Herts, UK; UCL, Université Catholique de Louvain, Belgium.

\begin{tabular}{|c|c|c|}
\hline Strain & Other strain designation(s) & Origin \\
\hline \multicolumn{3}{|l|}{$[P$.$] syzygii$} \\
\hline LMG 6969 & RAL08, Eden-Green S593 & \\
\hline LMG 6970 & RAL09, Eden-Green S594 & \\
\hline LMG $10661^{\mathrm{T}}$ & RAL10 ${ }^{\mathrm{T}}$, Eden-Green R001 ${ }^{\mathrm{T}}$, Jones W1330 ${ }^{\mathrm{T}}$, NCPPB $3446^{\mathrm{T}}$ & West Sumatra ('Syzygium aromaticum') \\
\hline LMG 10662 & RAL11, Eden-Green R002, NCPPB 3445 & West Java \\
\hline \multicolumn{3}{|l|}{ R. basilensis } \\
\hline LMG 18990* & DSM 11853, Steinle RK1 & Laboratory fixed bed reactor, 2,6-dichlorophenole as sole energy source \\
\hline \multicolumn{3}{|l|}{ R. eutropha } \\
\hline LMG 1194 & RAL14, CCUG13796, DSM 515, Schlegel B19 & USA, forest soil \\
\hline LMG $1199^{\mathrm{T}}$ & $\begin{array}{l}\text { RAL15 } 5^{\mathrm{T}} \text {, ATCC } 17697^{\mathrm{T}}, \text { CCUG } 1776^{\mathrm{T}}, \text { DSM } 531^{\mathrm{T}} \text {, } \\
\text { ICPB } 3984^{\mathrm{T}} \text {, NCIB } 11842^{\mathrm{T}}\end{array}$ & USA, soil \\
\hline LMG 1201 & $\begin{array}{l}\text { RAL16, ATCC } 17699 \text {, ATCC } 23440 \\
\text { CCUG } 13797, \text { DSM 428, NCIB } 10442, \\
\text { Schlegel H16 }\end{array}$ & Göttingen, Germany, source sludge \\
\hline \multicolumn{3}{|l|}{ R. gilardii } \\
\hline LMG $5886^{\mathrm{T} *}$ & API $141-2-84^{\mathrm{T}}$, ATCC $700815^{\mathrm{T}}$, Gilardi $4325^{\mathrm{T}}$ & Whirlpool \\
\hline \multicolumn{3}{|c|}{ R. mannitolytica } \\
\hline LMG $6866^{\mathrm{T}}$ & NCIB $10805^{\mathrm{T}}$ & St. Thomas' Hospital, London, UK, 1971, blood \\
\hline LMG 19090 & LBV407, UCL310 & GUH, 1998, recurrent meningitis \\
\hline LMG 19091 & RAL13, LBV371, GUH 98063523 & GUH, 1998, abdominal haematoma \\
\hline LMG 19092 & PSE061, GUH S90 03985 & GUH, 1990, sputum \\
\hline \multicolumn{3}{|l|}{ R. paucula } \\
\hline LMG $3244^{\mathrm{T}}$ & ATCC $700817^{\mathrm{T}}$, CCUG $12507^{\mathrm{T}}$, CDC E6793 ${ }^{\mathrm{T}}$ & Oregon, USA, human respiratory tract \\
\hline LMG 3515 & CCUG 12411, CCUG 12505, CDC E8967, LMG 3245 & Georgia, USA, sputum \\
\hline \multicolumn{3}{|l|}{ R. pickettii } \\
\hline LMG 7001* & CCUG 3314, Pickett K-214 & USA, Sephadex eluate \\
\hline LMG 7002* & CCUG 3316, LMG 7146, Pickett K-279 & \\
\hline LMG 7008* & CCUG 2165 & Göteborg, Sweden, 1973, urine \\
\hline LMG $7145^{*}$ & CCUG 3315, Pickett K-232 & \\
\hline \multicolumn{3}{|c|}{ R. pickettii biovar Va-1 } \\
\hline LMG 7005 & CCUG 1467, CDC A5832, PSE056 & \\
\hline LMG 7014 & RAL02, CCUG 12491, Gilardi GLG 3963 & Blood \\
\hline LMG 7015 & RAL03, CCUG 12492, Gilardi GLG 3905 & Blood \\
\hline LMG 7160 & RAL01, CIP 74.22, CIP R866 & Blood culture \\
\hline LMG 19083 & ML7, RAL05 & Soil, Japan \\
\hline LMG 19084 & PSE058, GUH S89 04031 & GUH, 1989 , sputum \\
\hline LMG 19086 & PSE060, GUH S89 04266 & GUH, 1989 , sputum \\
\hline LMG 19088 & ML10, RAL06 & Soil, Japan \\
\hline \multicolumn{3}{|c|}{ R. pickettii biovar Va-2 } \\
\hline ATCC 27512 & WG076, Pickett K-550 & Patient with tracheotomy, 1973 \\
\hline LMG $5942^{\mathrm{T}}$ & $\begin{array}{l}\text { ATCC } 27511^{\mathrm{T}} \text {, CCUG } 3318^{\mathrm{T}} \text {, CIP } 73.23^{\mathrm{T}} \text {, ICPB } 3981^{\mathrm{T}}, \mathrm{JCM} 5969^{\mathrm{T}} \text {, } \\
\text { NCTC } 11149^{\mathrm{T}} \text {, Pickett K-288 }, \text { PSE } 055^{\mathrm{T}} \text {, WG } 071^{\mathrm{T}}\end{array}$ & Los Angeles, CA, USA, patient with tracheotomy \\
\hline LMG 19085 & RAL12, GUH 99034045 & GUH, 1999, nebulizer \\
\hline \multicolumn{3}{|c|}{ R. solanacearum } \\
\hline LMG $2299^{\mathrm{T}}$ & $\begin{array}{l}\text { RAL17 } 17^{\mathrm{T}} \text {, CCUG } 14272^{\mathrm{T}}, \text { DSM } 9544^{\mathrm{T}} \text {, } \\
\text { JCM } 10489^{\mathrm{T}} \text {, Kelman } 60-1^{\mathrm{T}}, \text { NCPPB } 325^{\mathrm{T}}\end{array}$ & USA, Lycopersicon esculentum \\
\hline LMG 2303 & RAL18, NCPPB 078 & Honduras \\
\hline \multicolumn{3}{|l|}{ Ralstonia sp. } \\
\hline LMG 19087 & YL13, RAL07 & Japan, soil \\
\hline LMG 19089 & MC5, RAL04 & Japan, soil \\
\hline
\end{tabular}

* Strain was only included in SDS-PAGE of whole-cell proteins.

was performed on an ABI 310 sequencer using the ABI Big Dye cycle sequencing reaction kit with AmpliTaq FS DNA polymerase (Perkin Elmer) with primers described previously (Coenye et al., 1999). Analysis of the sequences and clustering was done by using GENECOMPAR version 4.1 (Applied Maths).

DNA base composition. DNA was degraded enzymatically into nucleosides as described by Mesbah et al. (1989). The nucleoside mixture obtained was then separated by HPLC using a Waters Symmetry Shield C8 column thermostabilized at $37^{\circ} \mathrm{C}$. The solvent was $0.02 \mathrm{M} \mathrm{NH}_{4} \mathrm{H}_{2} \mathrm{PO}_{4}(\mathrm{pH}$
4.0) with $1.5 \%$ acetonitrile. Non-methylated lambda phage DNA (Sigma-Aldrich) was used as the calibration reference. DNA-DNA hybridizations. DNA-DNA hybridizations were performed with photobiotin-labelled probes in microplate wells as described by Ezaki et al. (1989), using an HTS7000 Bio Assay Reader (Perkin Elmer) for the fluorescence measurements (excitation filter of $360 \mathrm{~nm}$, emission filter of $465 \mathrm{~nm}$ ). The optimal renaturation temperature was determined according to the equation of De Ley et al. (1970).

PAGE of cell proteins. Cells were grown for $48 \mathrm{~h}$ on TSA at $37^{\circ} \mathrm{C}$. SDS protein extracts were prepared and electro- 
Table 2 Phenotypic characteristics useful in the differentiation of the Ralstonia species

The following taxa were included in the analysis: 1, R. mannitolytica strains LMG 6866 ${ }^{\mathrm{T}}$, LMG 19090, LMG 19091 and LMG 19092; 2, R. pickettii biovar Va-1 strains LMG 7014, LMG 7015, LMG 7160, LMG 19083, LMG 19084, LMG 19086 and LMG 19088; 3, R. pickettii biovar Va-2 strains ATCC 27512, LMG 5942 ${ }^{\mathrm{T}}$ and LMG 19085; 4, Ralstonia sp. strain LMG 19089; 5, Ralstonia sp. strain LMG 19087; 6, R. solanacearum strains LMG 2299 and LMG 2303; 7, R. eutropha strains LMG 1194, LMG $1199^{\mathrm{T}}$ and LMG 1201; 8, R. paucula strains LMG 3515 and LMG 3244 ; and 9, R. gilardii. Data for $R$. gilardii were taken from Coenye et al. (1999). R, Resistant; s, susceptible; NK, not known. Growth is scored as: v, variable; +, all strains positive; $(+)$, weakly positive; -, all strains negative.

\begin{tabular}{|c|c|c|c|c|c|c|c|c|c|}
\hline Characteristic & 1 & 2 & 3 & 4 & 5 & 6 & 7 & 8 & 9 \\
\hline Flagellation & Polar 1 & Polar 1 & Polar 1 & Polar 1 & Polar 1 & None & Peritrichal & Peritrichal & Polar 1 \\
\hline \multicolumn{10}{|l|}{ Reaction to: } \\
\hline Colistin & $\mathrm{R}$ & $\mathrm{R}$ & $\mathrm{R}$ & $\mathrm{R}$ & $\mathrm{R}$ & $\mathrm{R}$ & $\mathrm{s}$ & $\mathrm{s}$ & NK \\
\hline Desferrioxamine & $\mathrm{R}$ & $\mathrm{s}$ & $\mathrm{s}$ & $\mathrm{R}$ & $\mathrm{R}$ & $\mathrm{s}$ & $\mathrm{R}$ & $\mathrm{R}$ & NK \\
\hline $\begin{array}{l}\text { Viability on TSA at room } \\
\text { temperature }\end{array}$ & $<6 \mathrm{~d}$ & $<6 \mathrm{~d}$ & $<6 \mathrm{~d}$ & $<6 \mathrm{~d}$ & $<6 \mathrm{~d}$ & $<6 \mathrm{~d}$ & $>21 \mathrm{~d}$ & $>21 \mathrm{~d}$ & NK \\
\hline Growth at $42{ }^{\circ} \mathrm{C}$ & + & $\mathrm{v}$ & $\mathrm{v}$ & + & - & - & $\mathrm{v}$ & $\mathrm{v}$ & + \\
\hline Catalase & + & + & $+*$ & + & + & + & + & + & + \\
\hline Oxidase & + & $+*$ & $+*$ & + & + & + & + & + & - \\
\hline Alkaline phosphatase (Rosco) & - & - & - & - & - & - & + & $-\dagger$ & $+末$ \\
\hline Pyrrolidonyl arylamidase & + & + & + & + & + & - & + & + & NK \\
\hline Phenylalanine deaminase & vई & vई & + & vई & - & - & $\mathrm{v}$ & - & NK \\
\hline Urease & + & + & + & + & + & + & - & + & - \\
\hline Nitrate reduction & - & + & + & + & + & + & $\mathrm{v}$ & - & - \\
\hline Tween 80 hydrolysis & + & + & + & + & + & + & $\mathrm{v}$ & + & $\mathrm{NK}$ \\
\hline \multicolumn{10}{|l|}{ Production of acid from: } \\
\hline L-Arabinose & + & + & + & + & + & - & - & - & - \\
\hline D-Arabitol & + & - & - & + & + & - & - & - & NK \\
\hline Glucose & + & + & + & + & + & + & - & - & NK \\
\hline Inositol & - & - & - & - & - & + & - & - & NK \\
\hline Lactose & + & + & - & + & + & - & - & - & NK \\
\hline Maltose & + & + & - & + & + & - & - & - & NK \\
\hline Mannitol & + & - & - & + & + & - & - & - & NK \\
\hline Sucrose & - & - & - & - & - & + & - & - & NK \\
\hline D-Xylose & + & + & + & + & + & - & - & - & - \\
\hline \multicolumn{10}{|l|}{ Alkalinization of: } \\
\hline Acetate & + & + & + & + & + & - & + & + & NK \\
\hline Allantoin & & - & - & - & - & - & + & - & NK \\
\hline Citrate & + & + & + & + & + & + & + & + & - \\
\hline Galacturonate & + & + & + & + & + & + & - & - & NK \\
\hline Lactate & + & + & + & + & + & - & + & + & NK \\
\hline Maleate & - & + & + & - & $(+)$ & $\mathrm{v}$ & $\mathrm{v}$ & $\mathrm{v}$ & NK \\
\hline Malonate & + & + & + & + & + & - & + & + & NK \\
\hline Mucate & + & + & + & + & + & + & - & + & NK \\
\hline Oxalate & - & - & - & - & - & - & + & + & NK \\
\hline Tartrate & - & + & + & - & - & + & + & + & NK \\
\hline \multicolumn{10}{|l|}{ Assimilation of: } \\
\hline 3-Hydroxybenzoate & - & - & - & - & - & - & + & - & NK \\
\hline Caprate & + & + & + & + & + & - & + & + & - \\
\hline Propionate & + & + & + & + & + & - & + & + & NK \\
\hline Suberate & + & + & + & + & + & - & + & + & $\mathrm{NK}$ \\
\hline
\end{tabular}

* Negative according to Vandamme et al. (1999).

$\uparrow$ Negative with Rosco tablets, containing nitrophenyl phosphate as the substrate. Vandamme et al. (1999) reported a positive reaction, using API ZYM (naphthyl phosphate as the substrate). In this study, all strains tested with API ZYM were positive.

† Tested with API ZYM.

$\S$ Phenylalanine deaminase reactions were difficult to interpret (weakly positive) and very variable.

phoresed according to Pot et al. (1994) and the collected data were interpreted as described by Vauterin \& Vauterin (1992). The similarity between all pairs of electrophoresis patterns was calculated by the Pearson product-moment correlation coefficient, expressed as a percentage.

Determination of cellular fatty acid composition. Cellular fatty acids were extracted from cells grown for $48 \mathrm{~h}$ on TSA at $37^{\circ} \mathrm{C}$. The fatty acid analysis was performed at $45-210{ }^{\circ} \mathrm{C}$ by using a capillary column CP-Sil 88 (Chrompack International) and a Delsi DI 200 chromatograph (Intersmat) equipped with split-splitness injection and a flame-ionization detector. The results were expressed as relative percentages by using an Enica 31 integrator obtained from Delsi Nermag Instruments (Intersmat).

\section{RESULTS}

\section{Microbiology}

Strain LMG 19090, obtained from patient 1, was isolated on Burkholderia cepacia selective medium (Mast Diagnostics), containing $100 \mathrm{mg}$ ticarcillin $1^{-1}$ and $300 \mathrm{U}$ polymyxin $\mathrm{B} \mathrm{ml}^{-1}$. Testing with API $20 \mathrm{NE}$ resulted initially in identification as $P$. fluorescens 
Table 3 Cellular fatty acid composition ( $\mathrm{mol} \%$ )

\begin{tabular}{|c|c|c|c|c|c|}
\hline Taxon & Strains & $16: 1^{9 \text { cis }}$ & $16: 0$ & $18: 1^{11 \mathrm{cis}}$ & $14: 0$ \\
\hline R. mannitolytica & LMG 6866" LMG 19090, LMG 19091 & $30-38$ & $21-30$ & $7-15$ & $5-7$ \\
\hline R. pickettii biovar Va-1 & LMG 7160, LMG 7014, LMG 19084 & $41-42$ & $26-28$ & $13-15$ & 10 \\
\hline R. solanacearum & LMG 2299T, LMG 2303 & $41-42$ & $26-33$ & $9-13$ & $6-10$ \\
\hline R. eutropha & LMG 1194, LMG 1199", LMG 1201 & $41-46$ & $27-30$ & $14-18$ & $4-6$ \\
\hline R. paucula & LMG 3515, LMG $3244^{\mathrm{T}}$ & $42-44$ & $22-23$ & $17-20$ & $6-7$ \\
\hline
\end{tabular}

Table 4 DNA G + C content and DNA-DNA binding values of strains examined

\begin{tabular}{|c|c|c|c|c|c|c|c|c|c|c|}
\hline \multirow[t]{2}{*}{ Taxon } & \multirow{2}{*}{$G+C$ content $(\operatorname{mol} \%)$} & \multicolumn{9}{|c|}{ DNA-DNA binding with DNA from (\%): } \\
\hline & & 1 & 2 & 3 & 4 & 5 & 6 & 7 & 8 & 9 \\
\hline 1. R. mannitolytica LMG $6866^{\mathrm{T}}$ & $66 \cdot 2$ & 100 & & & & & & & & \\
\hline 2. R. mannitolytica LMG 19090 & $66 \cdot 2$ & 88 & 100 & & & & & & & \\
\hline 3. R. mannitolytica LMG 19091 & $66 \cdot 2$ & 86 & 100 & 100 & & & & & & \\
\hline 4. R. pickettii biovar Va-2 LMG $5942^{\mathrm{T}}$ & $64 \cdot 0$ & 58 & ND & ND & 100 & & & & & \\
\hline 5. R. pickettii biovar Va-2 LMG 19085 & $64 \cdot 1$ & 53 & 48 & 52 & 85 & 100 & & & & \\
\hline 6. Ralstonia sp. LMG 19089 & $65 \cdot 1$ & 56 & 58 & 57 & 64 & 64 & 100 & & & \\
\hline 7. R. pickettii biovar Va-1 LMG 19083 & $64 \cdot 1$ & 46 & ND & ND & 57 & 62 & 66 & 100 & & \\
\hline 8. R. pickettii biovar Va-1 LMG 19088 & $64 \cdot 1$ & 50 & ND & ND & 61 & 61 & 68 & 100 & 100 & \\
\hline 9. Ralstonia sp. LMG 19087 & $64 \cdot 0$ & 50 & ND & ND & 63 & 63 & 71 & 65 & 69 & 100 \\
\hline
\end{tabular}

ND, Not done.

(profile code 0054 555). Strain LMG 19091, obtained from patient 2, had been identified previously as $P$. fluorescens (API profile code 0045 555). Strain LMG 19092 (PSE061) was isolated in 1990 from the sputum of a neonate during an outbreak in the paediatric department and had been identified at that time as $R$. pickettii. The combined features of biochemical characteristics and colistin resistance indicated that these isolates were strains of $R$. mannitolytica sp. nov. (formerly Ralstonia pickettii biovar 3/'thomasii') (Clark et al., 1984; Gilligan, 1995).

The biochemical characteristics useful for the differentiation of Ralstonia species are summarized in Table 2. The three clinical $R$. mannitolytica strains were motile by a single polar flagellum, while motility was not observed for the culture collection $R$. mannitolytica type strain LMG $6866^{\mathrm{T}}$. During this study, it was observed that freshly isolated strains were very motile and that motility decreased upon prolonged preservation and subculture. The type strain of $R$. mannitolytica, LMG $6866^{\mathrm{T}}$, was non-motile, possibly as a consequence of prolonged preservation.

All four strains grew at 30,37 and $42{ }^{\circ} \mathrm{C}$ and were viable for less than $6 \mathrm{~d}$ on TSA at room temperature. Oxidase and catalase were positive. They were resistant to desferrioxamine, $\mathrm{O}: 129$ and colistin. No acid was produced from ethylene glycol. Urease, pyrrolidonyl arylamidase (Rosco), Tween esterase and phenylalanine deaminase were positive. Nitrate reduction, indole and hydrogen sulfide production, alkaline phosphatase (Rosco), arginine dihydrolase, lysine and ornithine decarboxylases and aesculin and gelatin hydrolysis were negative. Acid was produced oxidatively from glucose, L-arabinose, lactose, maltose, mannitol, D-arabitol and D-xylose. Alkalinization occurred on minimal mineral agar with acetate, serine, malonate, $\beta$-alanine, 4-aminobutyrate, azelate, succinate, fumarate, butyrate, formate, malate, mucate, galacturonate, citrate, histidine and lactate, but not with acetamide, adipate, alginate, allantoin, amygdalin, L-arginine, benzoate, L-ornithine, maleate or tartrate.

Testing by means of API 20NE, API 50CH and ID $32 \mathrm{GN}$ indicated that the strains assimilated acetate, $\mathrm{N}$ acetylglucosamine, L-alanine, L-arabinose, D-arabitol, 4-hydroxybenzoate, 3-hydroxybutyrate, caprate, citrate, fructose, galactose, gluconate, glucose, 2-ketogluconate, glycerol, histidine, D-lactate, malate, malonate, mannitol, L-proline, propionate, serine, suberate and D-xylose, but not adipate, amygdalin, Lfucose, glycogen, inositol, itaconate, 5-ketogluconate, maltose, mannose, melibiose, phenylacetate, rhamnose, ribose, sucrose, salicin, D-sorbitol or 3-hydroxybenzoate and confirmed the absence of nitrate reduction.

Using the API ZYM system, the following enzymes were detected: C4 esterase, C8 esterase-lipase, C14 lipase, leucine arylamidase, acidic and alkaline phos- 
T. De Baere and others

Table 5 16S rDNA sequences included in this study

\begin{tabular}{|c|c|c|c|}
\hline Taxon & 16S rDNA accession no. & $\begin{array}{l}\text { No. of nucleotides } \\
\text { sequenced }\end{array}$ & Reference(s) \\
\hline$[P$.$] syzygii$ & AB021403 & 1513 & - \\
\hline [P.] syzygii LMG $10661^{\mathrm{T}}$ & AJ270252 & 469 & This study \\
\hline [P.] syzygii LMG 6970 & AJ 270253 & 464 & This study \\
\hline$[P$.$] syzygii LMG 10662$ & AJ 270254 & 463 & This study \\
\hline$[P$.$] syzygii LMG 6969$ & $\mathrm{AJ} 270255$ & 449 & This study \\
\hline R. eutropha & M32021 & 1511 & - \\
\hline R. gilardii & AF076645 & 1451 & Coenye et al. (1999) \\
\hline R. mannitolytica LMG 19091 & $\mathrm{AJ} 270256$ & 1453 & This study \\
\hline R. mannitolytica LMG 19090 & AJ 270257 & 1450 & This study \\
\hline R. mannitolytica LMG 19092 & AJ 271437 & 517 & This study \\
\hline R. mannitolytica LMG $6866^{\mathrm{T}}$ & AJ 270258 & 1449 & This study \\
\hline R. paucula & AF085226 & 1484 & Vandamme et al. (1999) \\
\hline R. pickettii bv. Va-1 LMG 7160 & AJ270260 & 1450 & This study \\
\hline R. pickettii bv. Va-1 LMG 19083 & AB013428 & 441 & This study, Suyama et al. (1998) \\
\hline R. pickettii bv. Va-1 LMG 19088 & AB013429 & 447 & This study, Suyama et al. (1998) \\
\hline R. pickettii bv. Va-1 LMG 19084 & AJ270261 & 342 & This study \\
\hline R. pickettii bv. Va-1 LMG 7015 & AJ249848 & 458 & This study \\
\hline R. pickettii bv. Va-1 LMG 7005 & AJ 270262 & 424 & This study \\
\hline R. pickettii bv. Va-1 LMG 7014 & AJ270264 & 472 & This study \\
\hline R. pickettii bv. Va-1 LMG 19086 & AJ 270263 & 439 & This study \\
\hline R. pickettii bv. Va-1 & X70348 & 294 & Seal et al. (1993) \\
\hline R. pickettii & AB004790 & 1468 & - \\
\hline R. pickettii bv. Va-2 LMG $5942^{\mathrm{T}}$ & AJ 270265 & 474 & This study \\
\hline R. pickettii bv. Va-2 LMG $5942^{\mathrm{T}}$ & S55004 & 970 & Yabuuchi et al. (1992) \\
\hline R. pickettii bv. Va-2 ATCC 27512 & X67042 & 1417 & Li et al. (1993) \\
\hline R. pickettii bv. Va-2 LMG 19085 & AJ270266 & 450 & This study \\
\hline R. pickettii bv. Va-2 & X70349 & 294 & Seal et al. (1993) \\
\hline R. solanacearum & X67036 & 1434 & Li et al. (1993) \\
\hline Ralstonia sp. LMG 19089 & AJ270259 & 1455 & This study, Suyama et al. (1998) \\
\hline Ralstonia sp. LMG 19087 & AB01438 & 447 & This study, Suyama et al. (1998) \\
\hline CDC group IVc-2 strain & AF098288 & 1495 & Moissenet et al. (1999) \\
\hline CDC group IVc-2 strain & AF067657 & 1527 & Osterhout et al. (1998) \\
\hline Alcaligenes faecalis & M22508 & 1475 & Dewhirst et al. (1989) \\
\hline Brevundimonas diminuta & M59064 & 1445 & - \\
\hline Burkholderia andropogonis & X67037 & 1435 & Li et al. (1993) \\
\hline Burkholderia caryophylli & X67039 & 1420 & Li et al. (1993) \\
\hline Burkholderia cepacia & M22518 & 1473 & Dewhirst et al. (1989) \\
\hline Burkholderia gladioli & X67038 & 1434 & Li et al. (1993) \\
\hline Burkholderia mallei & S55008 & 378 & Yabuuchi et al. (1992) \\
\hline Burkholderia mallei & S55000 & 962 & Yabuuchi et al. (1992) \\
\hline Comamonas testosteroni & M11224 & 1563 & Yang et al. (1985) \\
\hline Pseudomonas aeruginosa & X06684 & 1537 & Toschka et al. (1988) \\
\hline
\end{tabular}

bv., Biovar.

phatase and phosphoamidase. Valine arylamidase, cystine arylamidase, trypsin, $\alpha$-chymotrypsin, $\alpha$ - and $\beta$-galactosidase, $\beta$-glucuronidase, $\alpha$-and $\beta$-glucosidase, $N$-acetyl- $\beta$-glucosaminidase, $\alpha$-mannosidase and $\alpha$ fucosidase were not detected.

\section{Cellular fatty acid composition}

The cellular fatty acid composition was determined for R. mannitolytica strains LMG 6866 ${ }^{\mathrm{T}}$, LMG 19090 and LMG 19091. Table 3 presents the data in comparison with those obtained for other Ralstonia species. The principal components for the $R$. mannitolytica strains were 16:1 $1^{\text {cis }}$ (range 30-36 $\mathrm{mol} \%$ ) and 16:0 (range $21-30 \mathrm{~mol} \%$ ), with $7-15 \mathrm{~mol} \%$ of $18: 1^{11 \mathrm{cis}}$ and $5-7$ mol $\%$ of $14: 0$.

\section{DNA G + C content}

The DNA G + C content for all three $R$. mannitolytica strains tested was $66 \cdot 2 \mathrm{~mol} \%$ (Table 4 ), which was higher than the values obtained for the four $R$. pickettii 


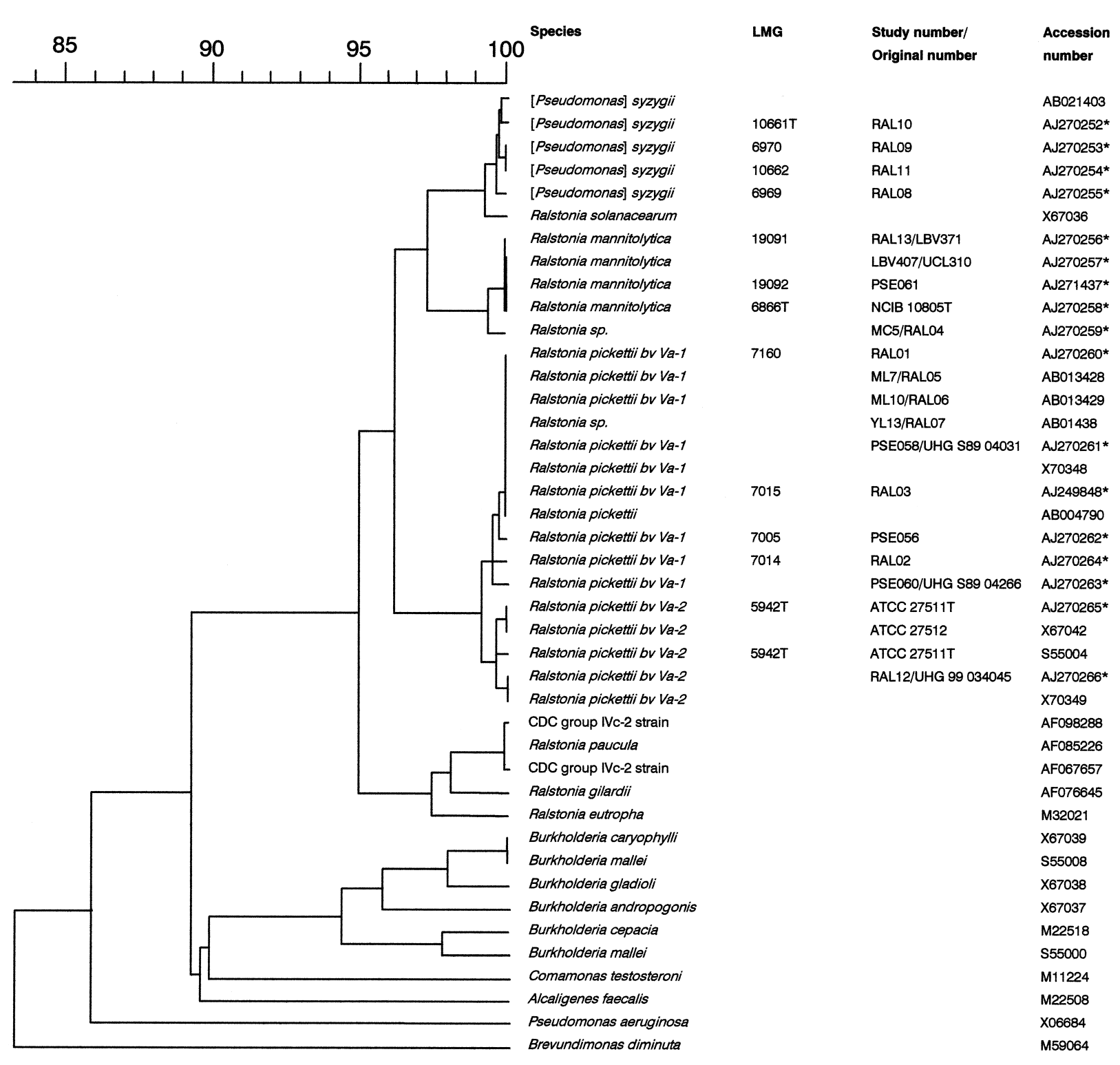

Fig. 1. Unweighted pair group method with averages (UPGMA) cluster analysis of the 165 rDNA sequences. Accession numbers indicated with asterisks refer to sequences determined in this study. The allocation of strains to either $R$. pickettii biovar Va-1 or Va-2 was done by testing acid production from maltose and lactose using OF medium: both positive for $R$. pickettii biovar Va-1 and both negative for $R$. pickettii biovar Va-2 (Pickett, 1994).

strains (64.0-64.1\%) and for the two unnamed Ralstonia strains $(64 \cdot 0$ and $65 \cdot 1 \%)$.

\section{$16 S$ rDNA sequence determination and total DNA homology}

The 16S rDNA sequences included in the analysis are listed in Table 5. The 16S rDNA sequences of the three clinical strains LMG 19090, LMG 19091 and LMG 19092 were identical and clustered at more than $99 \cdot 5 \%$ sequence similarity with the $R$. mannitolytica type strain, LMG $6866^{\mathrm{T}}$ (Fig. 1). DNA-DNA hybridization confirmed that these three strains belonged to the same species (Table 4).
Closest to this group, with a $16 \mathrm{~S}$ rDNA sequence similarity of more than $99 \%$, was strain LMG 19089 (MC5), which was originally isolated from a brown lowland soil (pH 6.0) near the sandy bank of the Kinu river, Hama, Mitsukaido-Shi, Ibaraki Prefecture, Japan, and which was found to degrade poly(hexamethylene carbonate) and poly( $\varepsilon$-caprolactone) and to accumulate poly(3-hydroxybutyrate) granules inside the cells (Suyama et al., 1998). However, the level of DNA-DNA hybridization with three $R$. mannitolytica strains was only $56-58 \%$ (Table 4), so it can be concluded that this strain probably belongs to a separate, as-yet unclassified species.

The $R$. solanacearum 16S rDNA sequence (GenBank 


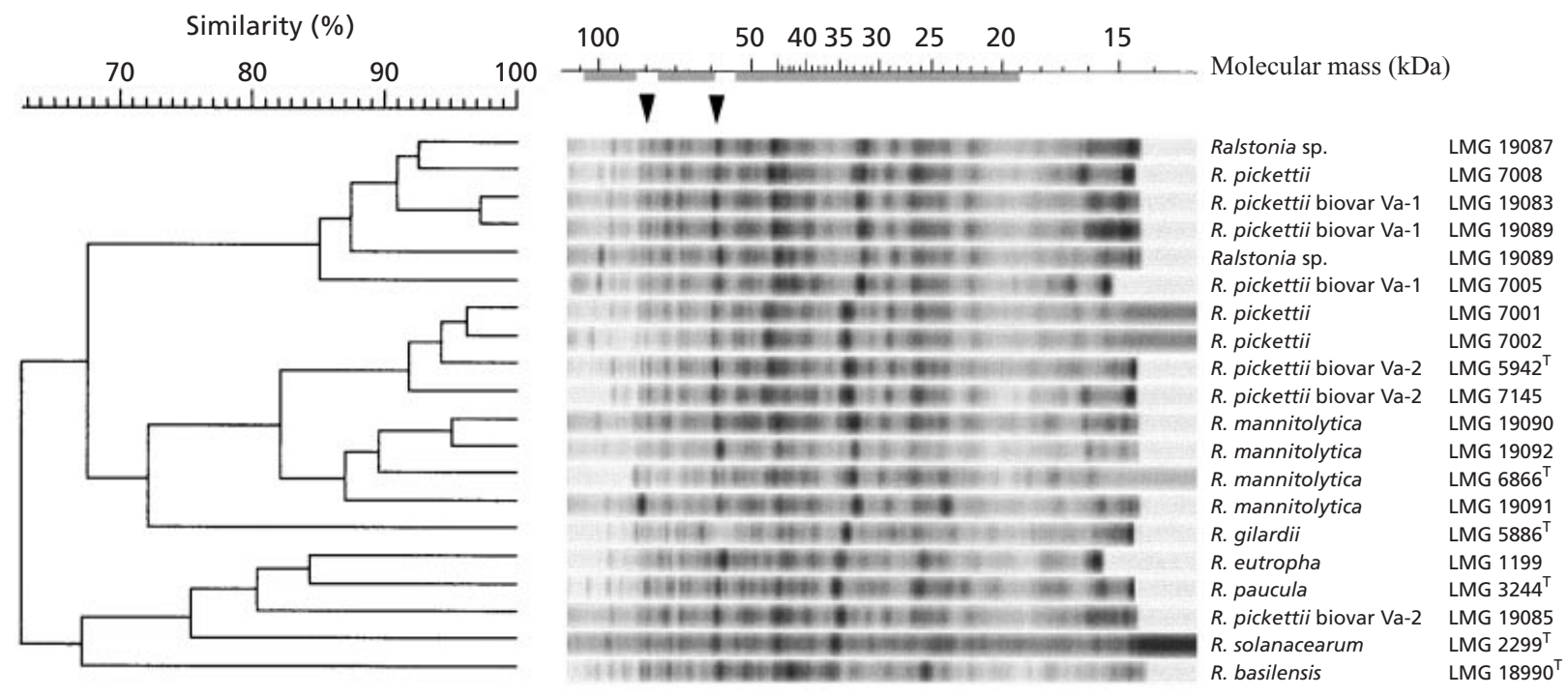

Fig. 2. Digitized representation of normalized SDS-PAGE protein profiles of different Ralstonia species and a dendrogram derived from the UPGMA linkage of correlation coefficients between the SDS-PAGE protein profiles of the strains studied. The zones indicated by arrowheads corresponding to molecular masses of approximately 60 and $80 \mathrm{kDa}$ were omitted from the clustering.

accession no. X67036) clustered at more than $99 \%$ similarity with the sequences obtained for the $[P$.] syzygii strains LMG 6969, LMG 6970, LMG $10661^{\mathrm{T}}$ and LMG 10662 (Fig. 1). LMG 19089 and the $R$. mannitolytica strains clustered with $R$. solanacearum $/[P$. $]$ syzygii at less than $98 \%$ rDNA sequence similarity. The 16S rDNA sequences for the $R$. pickettii biovar Va-1 and Va-2 strains clustered at $96 \%$ similarity versus the LMG 19089-R. mannitolytica- $R$. solanacearum $/[P$.] syzygii cluster. The sequences of $R$. paucula, $R$. gilardii and Ralstonia eutropha strains apparently formed a separate cluster at a similarity of less than $96 \%$ to $R$. pickettii, $R$. solanacearum/[P.] syzygii, strain LMG 19089 and $R$. mannitolytica. The available 16S rDNA sequences of Ralstonia group CDC IVc-2 strains [GenBank accession nos AF098288 (Moissenet et al., 1999) and AF067657 (Osterhout et al., 1998)] were found to be $100 \%$ identical to that of a $R$. paucula strain (Vandamme et al., 1999; GenBank accession no. AF085226). Sequence determination of the $5^{\prime}$ end of the $16 \mathrm{~S}$ rDNA revealed that the three $R$. pickettii strains found to produce no acid from maltose and lactose (i.e. $R$. pickettii biovar Va-2 strains) differed from the eight maltose and lactose acidificationpositive $R$. pickettii strains (i.e. $R$. pickettii biovar Va1 strains) at two positions. At Escherichia coli position 259 , the A observed for $R$. pickettii biovar Va-2 is replaced by $\mathrm{G}$ for $R$. pickettii biovar Va-1. The other transition is at $E$. coli position 269 , at which the $\mathrm{T}$ in the 16S rDNA sequence of $R$. pickettii biovar Va-2 is replaced by an $\mathrm{A}$ in $R$. pickettii biovar $\mathrm{Va}-1$. The differences in biochemistry and $16 \mathrm{~S}$ rDNA sequence are corroborated by the DNA-DNA hybridization data, since the two Japanese soil isolates (LMG 19083 and LMG 19088), which were identified as $R$. pickettii biovar Va-1 according to $16 \mathrm{~S}$ rDNA sequence and biochemical characteristics, showed only $57-62 \%$ DNA relatedness to the two $R$. pickettii biovar Va-2 strains included in the DNA-DNA hybridization studies (Table 4).

\section{PAGE of cell proteins}

SDS-PAGE largely confirmed the 16S rDNA sequence and the DNA-DNA hybridization data. Strains LMG 6866 ${ }^{\mathrm{T}}$, LMG 19090 and LMG 19091 belonged to a cluster with internal similarity of more than $80 \%$, well separated from all other reference and non-reference strains. This grouping was only obtained when two small zones at $60 \mathrm{kDa}( \pm 1 \mathrm{kDa})$ and $80 \mathrm{kDa}$ $( \pm 1 \mathrm{kDa})$, which contained a heavy protein band in the patterns of strains LMG 19090 and LMG 19091, were excluded from the similarity calculations (Fig. 2).

\section{DISCUSSION}

\section{Clinical relevance of $R$. mannitolytica}

A limited number of cases of hospital outbreaks with 'Pseudomonas thomasii' and R. pickettii biovar $3 /$ 'thomasii' isolates have been reported in the literature (Baird et al., 1976; Phillips et al., 1972; Dowsett, 1972; Pan et al., 1992). The first report (Phillips et al., 1972) dealt with bacteraemia and bacteriuria in 25 patients due to the administration of parenteral fluids prepared at the hospital pharmacy, where deionized water contaminated with ' $P$. thomasii' had been used (Phillips et al., 1972; Phillips \& Eykyn, 1972). Pan et al. (1992) reported that 23 of $39 R$. pickettii isolates from 
an epidemic involving 24 patients that was caused by contaminated saline solution (prepared by the hospital pharmacy) belonged to ' $P$. thomasii'.

The clinical importance of $R$. mannitolytica may have been overlooked, possibly due to misidentification as $P$. fluorescens, which does not lead to further investigation since this organism is usually considered to be a contaminant. Indeed, after strain LMG 19090, initially identified as $P$. fluorescens (API profile code 0054 555), had been recognized as $R$. mannitolytica because of colistin resistance and further biochemical testing, we studied retrospectively the only other strain (LMG 19091) in the GUH collection that had been stored as $P$. fluorescens (API profile code 0045 555) and could identify it also as $R$. mannitolytica. Thus, microbiologists should consider the possibility of an identification as $R$. mannitolytica for colistin-resistant $P$. fluorescens isolates. Strain LMG 19092 belonged to a collection of strains that had been catalogued previously as belonging to an $R$. pickettii outbreak at the GUH in 1990 and thus adds to the number of nosocomial outbreaks caused by $R$. mannitolytica.

\section{Differentiation of $\boldsymbol{R}$. mannitolytica at the species and genus level}

The distinctiveness of $R$. mannitolytica and R. pickettii biovar Va-1 and biovar Va-2 has been recognized previously. Although the study of King et al. (1979) was not conclusive and failed to establish ' $P$. thomasii' as a valid species, Costas et al. (1990) concluded that SDS-PAGE of whole-cell proteins provided clear evidence that $R$. pickettii and ' $P$. thomasii' were separate taxa, a finding confirmed by this study. On the other hand, Pan et al. (1992) reported that HPLC analysis of cell wall fatty acids could not distinguish $R$. pickettii biovar Va-1 from $R$. pickettii biovar $3 /$ 'thomasii', findings also confirmed by this study.

Several clear phenotypic differences exist between $R$. mannitolytica and the other Ralstonia species. $R$. mannitolytica can be differentiated from the other Ralstonia species, except for Ralstonia sp. strains LMG 19089 (RAL04/MC5) and LMG 19087 (RAL07/ YL13), through its assimilation/acidification of mannitol and D-arabitol. R. mannitolytica strains differ from $R$. pickettii and $R$. solanacearum by their resistance towards desferrioxamine and from $R$. pickettii because of their lack of alkalinization of tartrate and of nitrate reductase. The $R$. pickettii biovars $\mathrm{Va}-1$ and Va-2 differ from each other by the lack of acid production from maltose and lactose for $R$. pickettii biovar Va-2 strains. The $R$. solanacearum strains tested could be differentiated from other species by acidification/assimilation of inositol and sucrose and lack of pyrrolidonyl arylamidase and of assimilation of caprate, malonate, propionate, suberate, acetate and lactate. $R$. eutropha strains were positive for alkaline phosphatase (Rosco) and assimilation of 3hydroxybenzoate but did not alkalinize mucate, in contrast to the other Ralstonia species. R. paucula strains differed from $R$. eutropha and $R$. gilardii by strong urease production and from $R$. eutropha (no data available for $R$. gilardii) by alkalinization of mucate but not of adipate and allantoin. Strains of $R$. mannitolytica were previously reported to be adonitol and ethanol acidification-negative, like the $R$. pickettii biovars Va-1 and Va-2, and cellobiose-positive, like $R$. pickettii biovar Va-1 (Pickett, 1994).

Yabuuchi et al. (1995) pointed to the difficulty of establishing reliable features to differentiate Ralstonia from Burkholderia at the generic level and stated that the three Ralstonia species (R. pickettii, R. eutropha and $R$. solanacearum) did not assimilate the carbohydrates galactose, mannitol, mannose or sorbitol, while the 11 Burkholderia species did. However, $R$. mannitolytica also assimilates and acidifies mannitol. As a consequence, differentiation between $R$. mannitolytica and B. cepacia genomovar II strains, which do not decarboxylate lysine or acidify sucrose (Vandamme et al., 1997), is difficult, since $R$. mannitolytica and B. cepacia both produce acid from the same carbohydrates (with the exception of sucrose: $87 \%$ of B. cepacia strains are positive, whereas $R$. mannitolytica strains are negative) and since $R$. mannitolytica strains are unable to reduce nitrates, with $B$. cepacia strains unable to reduce nitrate to molecular nitrogen and with one-third of the B. cepacia strains reducing nitrate only to nitrite. Differentiation is only possible by means of a positive pyrrolidonyl arylamidase test for $R$. mannitolytica. Furthermore, in the routine clinical laboratory, $R$. mannitolytica can be differentiated from P. fluorescens and Pseudomonas aeruginosa by a negative pyoverdin test and from $P$. fluorescens by its inability to grow on Salmonella/ Shigella agar and by a negative arginine dihydrolase test.

The Japanese environmental isolates LMG 19087 and LMG 19089 were phenotypically indistinguishable from each other, but according to 16S rDNA sequence and DNA-DNA hybridization studies they belong to two separate, as-yet undescribed Ralstonia species. LMG 19089 clusters most closely to $R$. mannitolytica according to its partially determined 16S rDNA sequence. In SDS-PAGE, it clusters close to R. pickettii biovar Va-1. Both strains can be differentiated from $R$. mannitolytica only by their ability to reduce nitrate and LMG 19087 also by lack of growth at $42{ }^{\circ} \mathrm{C}$. LMG 19087 falls within the $R$. pickettii biovar Va-1 cluster according to its $16 \mathrm{~S}$ rDNA sequence.

The Japanese environmental isolates LMG 19083 and LMG 19088 could be identified biochemically and according to $16 \mathrm{~S}$ rDNA sequence and SDS-PAGE profile as genuine $R$. pickettii biovar Va-1 strains.

$R$. pickettii biovars $\mathrm{Va}-1$ and $\mathrm{Va}-2$ are easily distinguishable biochemically and some unambiguous 16S rDNA sequence differences are present, as shown in this study. DNA-DNA hybridization, as carried out here, separates the two representatives of each group tested, although Pickett \& Greenwood (1980) found 
$84 \%$ DNA homology between a Va-1 strain and the type strain of $R$. pickettii (which is a Va-2 group strain) and Ralston et al. (1973) found $90 \%$ binding at $71{ }^{\circ} \mathrm{C}$ between Va-1 and Va-2 strains. In the SDS-PAGE clustering of whole-cell proteins, the $R$. pickettii strains seem somewhat heterogeneous, without clear-cut delineation between biovar Va-1 and biovar Va-2 strains.

Comparative 16S rDNA sequence analysis indicates that two sublineages may be discriminated within the genus Ralstonia, with the $R$. eutropha lineage on the one hand, which is composed of $R$. eutropha, $R$. paucula and $R$. gilardii, and the $R$. pickettii lineage on the other hand, with $R$. pickettii, $R$. solanacearum, $R$. mannitolytica and $[P$.] syzygii. This genotypic discrimination is supported by at least some phenotypic differences. Members of the $R$. eutropha lineage are colistin susceptible, do not produce acids from carbohydrates, assimilate oxalate but not galacturonate and have peritrichous flagella in contrast to members of the $R$. pickettii lineage, which are colistin resistant, have a polar flagellum and have biochemical characteristics distinct from those mentioned for the $R$. eutropha lineage. They also differ in viability on TSA at room temperature, with viability of at most $6 \mathrm{~d}$ for the $R$. pickettii lineage and at least $21 \mathrm{~d}$ for the $R$. eutropha lineage. Incomplete data are available for $R$. gilardii, which belongs to the $R$. eutropha lineage according to 16S rDNA sequence analysis, although it was reported to be monotrichous (Coenye et al., 1999). Further studies, also including $R$. gilardii and $R$. basilensis, will indicate whether these findings can be confirmed.

\section{Description of Ralstonia mannitolytica sp. nov.}

Ralstonia mannitolytica (man.ni.to'ly.ti.ca. N.L. adj. mannitolytica cleaving mannitol).

The species accommodates the Ralstonia pickettii biovar 3/'thomasii' strains and at least some of the strains known as 'Pseudomonas thomasii'. Cells are Gram-negative, non-sporulating rods that are motile by means of one polar flagellum (motility was not observed for the culture collection $R$. mannitolytica type strain, LMG $6866^{\mathrm{T}}$ ). Aerobic growth is observed at 30,37 and $42{ }^{\circ} \mathrm{C}$ and strains are viable for less than $6 \mathrm{~d}$ on TSA at room temperature. Catalase and oxidase tests are positive. Nitrate and nitrite are not reduced. Strains are resistant to desferrioxamine, O:129 and colistin. No acid is produced from ethylene glycol. Urease, pyrrolidonyl arylamidase (Rosco), Tween esterase and phenylalanine deaminase tests are positive. Indole and hydrogen sulfide production, alkaline phosphatase (Rosco), arginine dihydrolase, lysine and ornithine decarboxylases, aesculin and gelatin hydrolysis tests are negative. Acid is produced oxidatively from glucose, L-arabinose, lactose, maltose, mannitol, D-arabitol and D-xylose. Alkalinization occurs on minimal mineral agar with acetate, serine, malonate, $\beta$-alanine, 4-aminobutyrate, azelate, succinate, fumarate, butyrate, formate, malate, mucate, galacturonate, citrate, histidine and lactate, but not with acetamide, adipate, alginate, allantoin, amygdalin, Larginine, benzoate, L-ornithine, maleate or tartrate. Testing by means of API 20NE, API 50CH and ID $32 \mathrm{GN}$ indicates that the strains assimilate acetate, $\mathrm{N}$ acetylglucosamine, L-alanine, L-arabinose, D-arabitol, 4-hydroxybenzoate, 3-hydroxybutyrate, caprate, citrate, fructose, galactose, gluconate, glucose, 2ketogluconate, glycerol, histidine, D-lactate, malate, malonate, mannitol, L-proline, propionate, serine, suberate and D-xylose, but not adipate, amygdalin, Lfucose, glycogen, inositol, itaconate, 5-ketogluconate, maltose, mannose, melibiose, phenylacetate, rhamnose, ribose, sucrose, salicin, D-sorbitol or 3hydroxybenzoate. Using the API ZYM system, the following enzymes are detected: C4 esterase, C8 esterase-lipase, C14 lipase, leucine arylamidase, acidic and alkaline phosphatase and phosphoamidase. Valine arylamidase, cystine arylamidase, trypsin, $\alpha$-chymotrypsin, $\alpha$ - and $\beta$-galactosidase, $\beta$-glucuronidase, $\alpha$ and $\beta$-glucosidase, $N$-acetyl- $\beta$-glucosaminidase, $\alpha$ mannosidase and $\alpha$-fucosidase are not detected. The following cellular fatty acid components are present: $16: 1^{9 \mathrm{cis}}$ (range 30-38 $\left.\mathrm{mol} \%\right), 16: 0(21-30 \mathrm{~mol} \%)$, $18: 1^{11 \mathrm{cis}}(7-15 \mathrm{~mol} \%)$ and $14: 0(5-7 \mathrm{~mol} \%)$. The DNA $\mathrm{G}+\mathrm{C}$ content is $66 \cdot 2 \mathrm{~mol} \%$.

The type strain is LMG $6866^{\mathrm{T}}$ (deposited as 'Pseudomonas thomasii' in 1972) (= NCIB $\left.10805^{\mathrm{T}}\right)$ (Phillips et al., 1972). The R. mannitolytica strains used in this study have been deposited in the BCCM/LMG Bacteria Collection (Laboratorium voor Microbiologie Ghent, Belgium) as LMG 19090, LMG 19091 and LMG 19092.

\section{ACKNOWLEDGEMENTS}

This work was partly supported by the Concerted Research Action of the "Ministerie van de Vlaamse Gemeenschap, Bestuur Wetenschappelijk onderzoek' (Belgium), grant no. 12050797. P.D.V. and M.V. are indebted to the Fund for Scientific Research for a position as Research Director and for research grants. Leen Van Simaey and Filippe Grillaert are acknowledged for excellent technical assistance. We also thank P. Green for strain information.

\section{REFERENCES}

Baird, R. M., Elhag, K. M. \& Shaw, E. J. (1976). Pseudomonas thomasii in a hospital distilled-water supply. J Med Microbiol $\mathbf{9}$, 493-495.

Brim, H., Heyndrickx, M., De Vos, P., Wilmotte, A., Springael, D., Schlegel, H. G. \& Mergeay, M. (1998). Amplified rDNA restriction analysis and further genotypic characterisation of metal-resistant soil bacteria and related facultative hydrogenotrophs. Syst Appl Microbiol 22, 258-268.

Clark, W. A., Hollis, D. G., Weaver, R. E. \& Riley, P. (1984). Identification of Unusual Pathogenic Gram-negative Aerobic and Facultatively Anaerobic Bacteria. Atlanta, GA: US Department of Health and Human Services, Public Health Service, Centers for Disease Control.

Coenye, T., Falsen, E., Vancanneyt, M., Hoste, B., Govan, J. R. W., Kersters, K. \& Vandamme, P. (1999). Classification of Alcaligenes 
faecalis-like isolates from the environment and human clinical samples as Ralstonia gilardii sp. nov. Int J Syst Bacteriol 49, 405-413.

Costas, M., Holmes, B., Sloss, L. L. \& Heard, S. (1990). Investigation of a pseudo-outbreak of 'Pseudomonas thomasii' in a special-care baby unit by numerical analysis of SDS-PAGE protein patterns. Epidemiol Infect 105, 127-137.

De Ley, J., Cattoir, H. \& Reynaerts, A. (1970). The quantitative measurement of DNA hybridization from renaturation rates. Eur J Biochem 12, 133-142.

Dewhirst, F. E., Paster, B. J. \& Bright, P. L. (1989). Chromobacterium, Eikenella, Kingella, Neisseria, Simonsiella, and Vitreoscilla species comprise a major branch of the beta group Proteobacteria by $16 \mathrm{~S}$ ribosomal ribonucleic acid sequence comparison: transfer of Eikenella and Simonsiella to the family Neisseriacae (emend.). Int J Syst Bacteriol 39, 258-266.

Dimech, W. J., Hellyar, A. G., Kotiw, M., Marcon, D., Ellis, S. \& Carson, M. (1993). Typing of strains from a single-source outbreak of Pseudomonas pickettii. J Clin Microbiol 31, 3001-3006.

Dowsett, E. (1972). Hospital infections caused by contaminated fluids. Lancet i, 1338.

Ezaki, T., Hashimoto, Y. \& Yabuuchi, E. (1989). Fluorometric deoxyribonucleic acid-deoxyribonucleic acid hybridization in microdilution wells as an alternative to membrane filter hybridization in which radioisotopes are used to determine genetic relatedness among bacterial strains. Int J Syst Bacteriol 39, 224-229.

Fass, R. J. \& Barnishan, J. (1976). Acute meningitis due to a Pseudomonas-like group Va-1 bacillus. Ann Intern Med 84, 51-52.

Fujita, S., Yoshida, T. \& Matsubara, F. (1981). Pseudomonas pickettii bacteremia. J Clin Microbiol 13, 781-782.

Gardner, S. \& Shulman, S. T. (1984). A nosocomial common source outbreak caused by Pseudomonas pickettii. Pediatr Infect Dis J 3, 420-422.

Gilligan, P. H. (1995). Pseudomonas and Burkholderia. In Manual of Clinical Microbiology, 6th edn, pp. 509-519. Edited by P. R. Murray, E. J. Baron, M. A. Pfaller, F. C. Tenover \& R. H. Yolken. Washington, DC: American Society for Microbiology.

Kahan, A., Philippon, A., Paul, G., Weber, S., Richard, C., Hazebroucq, G. \& Degeorges, M. (1983). Nosocomial infections by chlorhexidine solution contaminated with Pseudomonas pickettii (biovar Va-1). J Infect 7, 256-263.

King, A., Holmes, B., Phillips, I. \& Lapage, S. P. (1979). A taxonomic study of clinical isolates of Pseudomonas pickettii, 'P. thomasii' and 'Group IVd' bacteria. J Gen Microbiol 114, 137-147.

Kodaka, H., Armfield, A. Y., Lombard, G. L. \& Dowell, V. R., Jr. (1982). Practical procedure for demonstrating bacterial flagella. J Clin Microbiol 16, 948-952.

Lacey, S. \& Want, S. V. (1991). Pseudomonas pickettii infections in a paediatric oncology unit. J Hosp Infect 17, 45-51.

Li, X., Del Dot, T., Dorsh, M., Stackebrandt, E., Sly, L. I. \& Hayward, A. C. (1993). Phylogenetic studies on rRNA group II Pseudomonas using 16S rRNA sequences. J Appl Bacteriol 74, 324-329.

Lindsay, J. A. \& Riley, T. V. (1991). Susceptibility to desferrioxamine: a new test for the identification of Staphylococcus epidermidis. J Med Microbiol 35, 45-48.

Mesbah, M., Premachandran, U. \& Whitman, W. B. (1989). Precise measurement of the $\mathrm{G}+\mathrm{C}$ content of deoxyribonucleic acid by high-performance liquid chromatography. Int $J$ Syst Bacteriol 39, 159-167.

Moissenet, D., Goujon, C. P., Garbarg-Chenon, A. \& Vu-Thien, H. (1999). CDC group IVc-2: a new Ralstonia species close to Ralstonia eutropha. J Clin Microbiol 37, 1777-1781.

Osterhout, G. J., Valentine, J. L. \& Dick, J. D. (1998). Phenotypic and genotypic characterization of clinical strains of CDC group IVc-2. J Clin Microbiol 36, 2618-2622.

Pan, H. J., Teng, L. J., Tzeng, M. S., Chang, S. C., Ho, S. W., Luh, K. T. \& Hsieh, W. C. (1992). Identification and typing of Pseudomonas pickettii during an episode of nosocomial outbreak. Chin $J$ Microbiol Immunol 25, 115-123 (in Chinese).

Phillips, I. \& Eykyn, S. (1972). Contaminated drip fluids. Brit Med $J$ i, 746 .

Phillips, I., Eykyn, S. \& Laker, M. (1972). Outbreak of hospital infection caused by contaminated autoclaved fluids. Lancet i, $1258-1260$.

Pickett, M. J. (1994). Typing of strains from a single-source outbreak of Pseudomonas pickettii. J Clin Microbiol 32, $1132-1133$.

Pickett, M. J. \& Greenwood, J. R. (1980). A study of the Va-1 group of pseudomonads and its relationship to Pseudomonas pickettii. J Gen Microbiol 120, 439-446.

Pot, B., Vandamme, P. \& Kersters, K. (1994). Analysis of electrophoretic whole organism protein fingerprints. In Chemical Methods in Prokaryotic Systematics, pp. 493-521. Edited by M. Goodfellow \& A. G. O'Donnell. Chichester: Wiley.

Ralston, E., Palleroni, N. J. \& Doudoroff, M. (1973). Pseudomonas pickettii, a new species of clinical origin related to Pseudomonas solanacearum. Int J Syst Bacteriol 23, 15-19.

Raveh, D., Simhon, A., Gimmon, Z., Sacks, T. \& Shapiro, M. (1993). Infections caused by Pseudomonas pickettii in association with permanent indwelling intravenous devices: four cases and a review. Clin Infect Dis 17, 877-880.

Riley, P. S. \& Weaver, R. E. (1975). Recognition of Pseudomonas pickettii in the clinical laboratory: biochemical characterization of 62 strains. J Clin Microbiol 1, 61-64.

Roberts, L. A., Collignon, P. J., Cramp, V. B., Alexander, S., McFarlane, A. E., Graham, E., Fuller, A., Sinickas, V. \& Hellyar, A. (1990). An Australia-wide epidemic of Pseudomonas pickettii bacteraemia due to contaminated 'sterile' water for injection. Med J Aust 152, 652-655.

Seal, S. E., Jackson, L. A., Young, J. P. W. \& Daniels, M. J. (1993). Differentiation of Pseudomonas solanacearum, Pseudomonas syzygii, Pseudomonas pickettii and the Blood Disease Bacterium by partial $16 \mathrm{~S}$ rRNA sequencing: construction of oligonucleotide primers for sensitive detection by polymerase chain reaction. J Gen Microbiol 139, 1587-1594.

Steinle, P., Stucki, G., Stettler, R. \& Hanselmann, K. W. (1998). Aerobic mineralization of 2,6-dichlorophenol by Ralstonia sp. strain RK1. Appl Environ Microbiol 64, 2566-2571.

Suyama, T., Tokiwa, Y., Ouichanpagdee, P., Kanagawa, T. \& Kamagata, Y. (1998). Phylogenetic affiliation of soil bacteria that degrade aliphatic polyesters available commercially as biodegradable plastics. Appl Environ Microbiol 64, 5008-5011.

Tatum, H. W., Ewing, W. H. \& Weaver, R. E. (1974). Miscellaneous Gram-negative bacteria. In Manual of Clinical Microbiology, 2nd edn, pp. 270-294. Edited by E. H. Lennette, E. H. Spaulding \& J. P. Truant. Washington, DC: American Society for Microbiology.

Toschka, H. Y., Hopfl, P., Ludwig, W., Schleifer, K. H., Ulbrich, N. 
\& Erdmann, V. A. (1988). Complete nucleotide sequence of a $16 \mathrm{~S}$ ribosomal RNA gene from Pseudomonas aeruginosa. Nucleic Acids Res 16, 2348.

Vandamme, P., Holmes, B., Vancanneyt, M. and 8 other authors (1997). Occurrence of multiple genomovars of Burkholderia cepacia in cystic fibrosis and proposal of Burkholderia multivorans sp. nov. Int J Syst Bacteriol 47, 1188-1200.

Vandamme, P., Goris, J., Coenye, T., Hoste, B., Janssens, D., Kersters, K., De Vos, P. \& Falsen, E. (1999). Assignment of Centers for Disease Control group IVc-2 to the genus Ralstonia as Ralstonia paucula sp. nov. Int J Syst Bacteriol 49, 663-669.

Vauterin, L. \& Vauterin, P. (1992). Computer aided objective comparison of electrophoretic patterns for grouping and identification of microorganisms. Eur J Microbiol 1, 37-41.

Verschraegen, G., Claeys, G., Meeus, G. \& Delanghe, M. (1985). Pseudomonas pickettii as a cause of pseudobacteremia. J Clin Microbiol 21, 278-279.

Wauters, G., Van Bosterhaut, B., Janssens, M. \& Verhaegen, J.
(1998). Identification of Corynebacterium amycolatum and other nonlipophilic fermentative corynebacteria of human origin. $J$ Clin Microbiol 36, 1430-1432.

Yabuuchi, E., Kosako, Y., Oyaizu, H., Yano, I., Hotta, H., Hashimoto, Y., Ezaki, T. \& Arakawa, M. (1992). Proposal of Burkholderia gen. nov. and transfer of seven species of the genus Pseudomonas homology group II to the new genus, with the type species Burkholderia cepacia (Palleroni and Holmes 1981) comb. nov. Microbiol Immunol 36, 1251-1275.

Yabuuchi, E., Kosako, Y., Yano, I., Hotta, H. \& Nishiuchi, Y. (1995). Transfer of two Burkholderia and an Alcaligenes species to Ralstonia gen. nov.: proposal of Ralstonia pickettii (Ralston, Palleroni and Doudoroff 1973) comb. nov., Ralstonia solanacearum (Smith 1896) comb. nov. and Ralstonia eutropha (Davis 1969) comb. nov. Microbiol Immunol 39, 897-904.

Yang, D., Oyaizu, Y., Oyaizu, H., Olsen, G. J. \& Woese, C. R. (1985). Mitochondrial origins. Proc Natl Acad Sci USA 82, 4443-4447. 